\title{
1 Jet electro-absorbers for the treatment of gaseous perchloroethylene
}

\section{wastes}

3

O. González-Pérez ${ }^{1,+}$, M. Muñoz-Morales ${ }^{2,+}$, F.L. Souza ${ }^{2}$, C. Saez², P. Cañizares ${ }^{2}$, M.A.

4 Rodrigo $^{2, *}$

$5{ }^{1}$ Universidad Nacional del Litoral, CONICET, Programa de Electroquímica Aplicada e 6 Ingeniería Electroquímica (PRELINE), Facultad de Ingeniería Química, Santiago del 7 Estero 2829, S3000AOM Santa Fe, Argentina

$8 \quad{ }^{2}$ Department of Chemical Engineering. Faculty of Chemical Sciences \& Technologies. 9 Universidad de Castilla La Mancha. Campus Universitario s/n 13071 Ciudad Real. Spain

\section{Abstract}

In this work, a novel jet electro-absorber is presented as an efficient process that combines absorption and electro-oxidation for the treatment of gaseous pollutants. This system, based on the Venturi effect, enhances the absorption of vapor wastes in absence of a mechanical compressor. It has been tested with a model organochlorine compound, perchloroethylene, that it is widely used as solvent and easily promoted to the gas phase because of its high vapor pressure. Results confirmed that the target compound can be absorbed into the electrolytic solutions proposed, being the efficiency highly influenced by the electrolyte / absorbent composition. Opposite to it was expected, it was also confirmed that the electrolysis does not mineralize the compound, but it promotes mainly the transformation of the raw pollutant into refractory products. Also, it was determined the paramount influence on the perchloroethylene removal pathway of the bubble size produced by jet absorbers with different throat width, even modifying the products

\footnotetext{
${ }^{+}$both authors contribute equally

* author to whom all correspondence should be addressed: Manuel.Rodrigo@uclm.es
} 
24 distribution. A gaseous intermediate, phosgene and carbon tetrachloride are promoted in

25 the electro-oxidation treatments with the larger bubbles, while jet aerator of fine bubble

26 promotes the synthesis of trichloroacetic acid mainly in the liquid phase. Finally,

27 intermediates and final products generated shed light on the mechanisms of the processes

28 involved: wet decomposition or electrochemical degradation of perchloroethylene.

29

30 Keywords: Perchloroethylene; jet- mixer; electro-absorption; absorption; electrolysis;

31 diamond electrode

32 
- Jet electro-absorption can be applied to remove volatile compounds.

- Higher concentrations were absorbed using methanol as solvent.

- Bubble size controlled by the throat width modifies the absorption behavior.

- Final products depend on current density tested.

- No mineralization but transformation of perchloroethylene into other products. 


\section{Introduction}

Scrubbing is a well-known absorption process used to treat gaseous wastes. This technology has been applied from the seventies to remove odors and harmful gases, such as hydrogen sulfide [1] and carbon dioxide [2] from gaseous streams using aqueous solution of various alkylamines [3]. As well, sodium hydroxide and sodium hypochlorite were found to be good active components to promote the absorption process [4]. More recently, it was also evaluated the simultaneous removal of other gaseous pollutants such as $\mathrm{NO}_{x}, \mathrm{SO}_{2}$ and $\mathrm{CO}_{2}$ with a composite absorbent $\left(\mathrm{NaClO}_{2} / \mathrm{Na}_{2} \mathrm{~S}_{2} \mathrm{O}_{8}\right)$ obtaining among $80 \%$ and $90 \%$ of efficiency [5]. These progressive advances in the treatment of those pollutants have promoted the application of absorbers, using strong oxidative streams as absorbents, in the treatment of gaseous emissions from wastewater treatment plants (WWTP), where various organosulfur compounds mixed with trace quantities of volatile organic compounds (VOC) are contained [6].

However, there are more potential applications of this technology in development. Thus, in recent years an increasing number of organochlorinated compounds are being detected in the environment $[7,8]$ because of the growth of population and the industrial development. These pollutants are motivating the search of systems capable to remove them efficiently, but proposed technologies were focused on the treatment in one media, gaseous media $[9,10]$ or liquid media $[11,12]$ and low attention has paid to the removal of unexpected VOCs generated in liquid streams because of the selected removal treatment or simple vaporization. This objective includes the development of treatment technologies capable to face the removal of pollutants with high vapor pressure contained in the gaseous streams [13].

Design of reactive absorbers is not easy: the absorption systems needs high residence times and a good hydrodynamic behavior is required to increase the mass transport, 
favoring the reduction in the size of systems. Recently, according to the requirements of improving the contact between gas and liquid phase, and avoiding excessive costs associated with the length of the absorption column or a compressor, a jet-aerator based on the Venturi effect was studied to supply oxygen to produce $\mathrm{H}_{2} \mathrm{O}_{2}$ for the electro-Fenton process in the absence of a compressor [14, 15]. With this novel approach, higher $\mathrm{H}_{2} \mathrm{O}_{2}$ generation rate and lower energy consumption were obtained in comparison with conventional electrolyzers.

Nevertheless, the absorption of the pollutants does not remove them but simply transfer polluting from a gas to a liquid and, sometimes, even they are transformed into more ubiquitous and toxic compounds. By other side, waste treatment processes also have their specific problems that cannot be solved just applying a simple technology. Biological [16], physico-chemical [17-19] and advanced oxidation processes (AOPs) [20, 21] are currently being evaluated to treat industrial effluents. These methods have different drawbacks as the toxicity for the biological communities, the low efficiency or sludge generated with technologies as coagulation and flocculation or the higher investment costs for the reagents and reactors in AOPs [22].

Electrochemical advanced oxidation processes (EAOPs) [23-25] provides a clear advantage as the use of electrons as a clean reagent. Among them, conductive-diamond electrochemical oxidation (CDEO) favors the production of large amounts of hydroxyl radicals by water oxidation on boron doped diamond (BDD) anodes [12, 26, 27]. Pollutants can be removed by direct electrolysis on the surface of electrodes and indirect electrolysis with the mediation of the oxidant species promoted [28].

Production of gaseous streams polluted with chlorinated organics is a serious problem that must be faced, not only associated directly to industrial processes but also to the spontaneous emissions of landfills or traffic jams in crowded cities. Previous research 
made by our group concluded that even during the application of remediation technologies, the production of such streams is, unfortunately, very frequent $[29,30,31]$, becoming a real problem to be solved for the real implementation of treatment technologies.

In this work, authors are describing and testing a novel jet electro-absorber [32] that combines the process of absorption of gaseous pollutants into a liquid stream (which acts simultaneously as absorbent and electrolyte) with BDD electrolysis, taking advantage of: 1) the low energy requirements of the jet-absorbers to transfer the pollutant into the electrolyte-absorbent and 2) the powerful radical generated during the electrolysis with BDD anodes. Perchloroethylene (PCE), a widely used solvent in many industrial activities [33], is chosen as a model pollutant due to its vapor pressure (18.5 $\mathrm{mm} \mathrm{Hg}$ at $\left.25^{\circ} \mathrm{C}\right)$ and water solubility $\left(150 \mathrm{mg} \mathrm{dm}^{-3}\right)[34,35]$ that enhances its transference to the vapor phase. Instead of using a pure gaseous stream of this product in the electroabsorbers tests, and in order to simulate a real case of study, a solution containing perchloroethylene is stripped to generate the gaseous effluent to be treated. The performance of the electro-absorption system using different types of absorbentelectrolytes, and the influence of the width of the throat in the absorption efficiency of the jet- absorbers, are evaluated in this study. To end up, the evolution of intermediates compounds during the absorption and the electro-absorption processes were reported to understand the behavior and reactivity of the parental compound.

\section{Materials and methods}

2.1. Chemicals. All chemicals, including perchloroethylene $\left(\mathrm{C}_{2} \mathrm{Cl}_{4}>99 \%\right)$ (a.r., SigmaAldrich), anhydrous sodium sulphate, phosphoric acid (85\%), sulfuric acid 99.8\%), sodium carbonate (a.r., Fluka, Spain), were analytical grade and used as received. Hexane 
analytic grade (a.r., Sigma-Aldrich, Spain) was used as mobile phase. Helium and nitrogen (Al Air Liquide España, S.A.) were used in gas chromatography and helium was filtered by a hydrocarbon cartridge filter (Thermo Fisher Scientific) before its use. Double deionized water (Millipore Milli-Q system, resistivity $=18.2 \mathrm{M} \Omega \mathrm{cm}$ at $25{ }^{\circ} \mathrm{C}$ ) was used to prepare all solutions.

2.2. Experimental set-up. The experimental electro-absorption set-up consisted of a jet aerator coupled with a conventional flow-pass electrochemical cell.

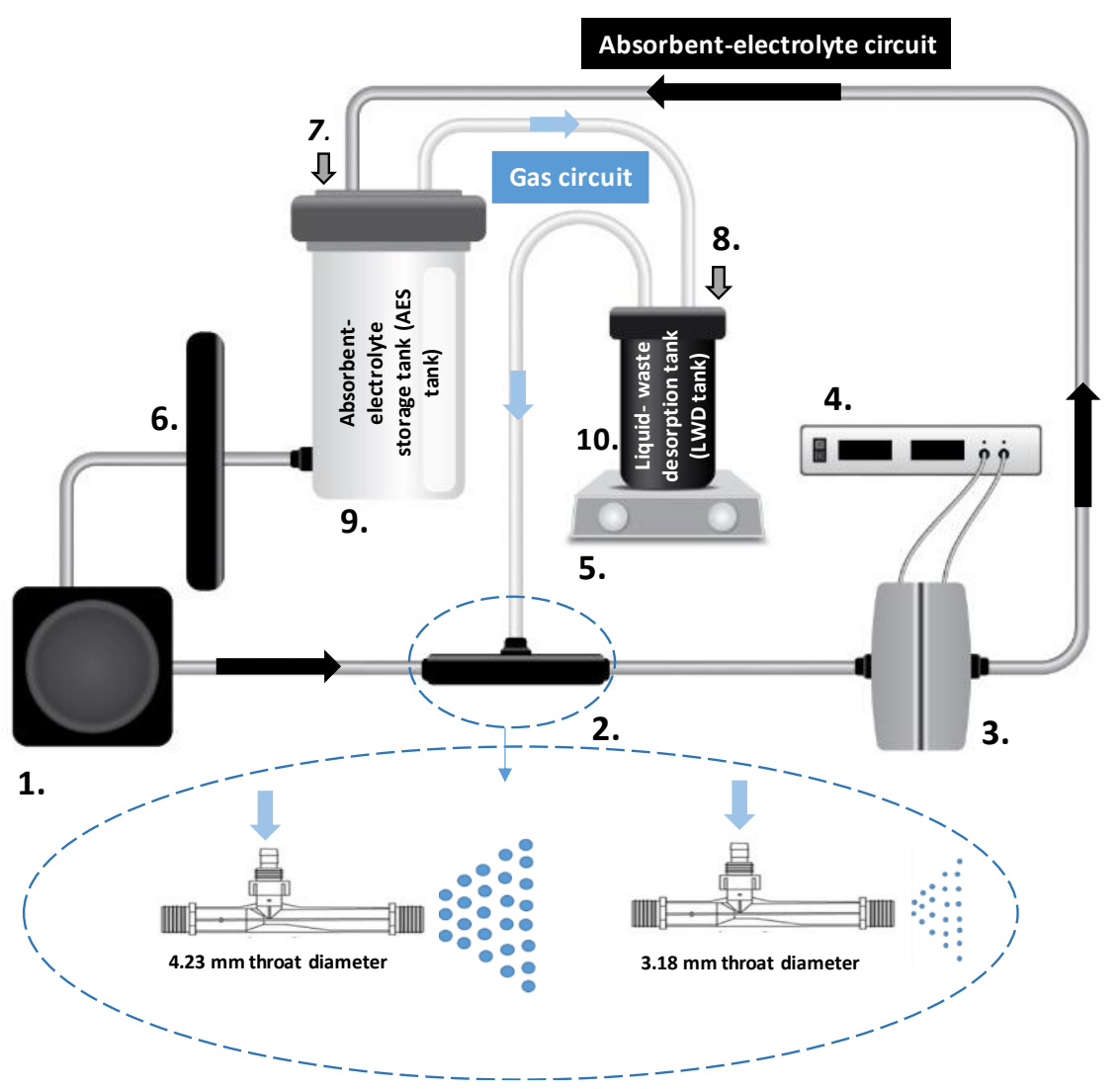

Figure 1. Schematic diagram of the absorption set-up with details of the different jetabsorbers evaluated. 1. Pump, 2. Jet aerator, 3. Electrochemical cell, 4. Power supply, 5. Magnetic Stirrer, 6. Rotameter, 7. Sampling point 1, 8. Sampling point 2, 9.Absorbent electrolyte storage (ABS) Tank, 10. Liquid Waste Desorption (LWD) Tank. 
128 To generate the gas polluted stream, in this study, instead of flowing directly the gaseous pollutant, it was simulated the emission of the pollutant by volatilization of the PCE contained in tank 10, where a concentrated solution of PCE is stored. To do this, the solution was stripped by connecting the gas inlet of the jet aerator (2) to the desorption tank (0). Thus, this allows the capture of the wet PCE and a more realistic simulation of the decontamination of a gaseous environment produced by perchloroethylene was attained. With this, the system can be divided in two connected circuits (Figure 1): liquid circuit namely "absorbent-electrolyte circuit" and gas circuit. To start with, the gas circuit uses the jet aerator (2) to favor the transference of volatilized PCE from LWD tank (10) to the liquid that acts as absorbent-electrolyte in the liquid circuit. The role of this tank (10) is not related to the treatment but it is to produce a more realistic gaseous pollutant flow, with real gaseous mixtures water-PCE, which can influence on the later treatment, as the reactivity of PCE in wet environments is known to be very important, although not well characterized yet [33]. Besides, there is a connection between the AES and LWD tanks (9 to 10) to equilibrate the total pressure of the system.

On the other hand, the absorbent-electrolyte circuit receives the pollutant stream by the jet aerator (2) and it is pumped with a centrifugal pump (1) to the electrochemical cell (3) connected to a power supply (4) to modify the composition of the produced liquid waste by electrochemically assisted processes. The other tank (so-called absorbent-electrolyte storage tank or AES tank, 9) was the auxiliary tank of the electrochemical cell (3) and the jet aerator (2), and its function was to provide residence time to the electrochemical cell in order to promote chemical reactions mediated by oxidants or reductants generated by the application of the electric current. The rotameter (6) indicates the total flow aimed and two sampling points were installed (7 and 8) to take liquid and gaseous samples in the tanks (9 and 10). 
Both, AES tank and LWD Tank (9 to 10) were made of polyvinyl chloride (PVC) with capacities of $2.5 \mathrm{dm}^{3}$ and $1 \mathrm{dm}^{3}$, respectively. The electrolytic solution that absorbs the pollutant (electrolyte-absorbent) contained initially $0.025 \mathrm{~mol} \mathrm{dm}^{-3}$ of $\mathrm{Na}_{2} \mathrm{SO}_{4}$ or $\mathrm{NaCl}$ as supporting electrolyte and the desorption tank was initially loaded with an aqueous solution of $100 \mathrm{mg} \mathrm{dm}^{-3}$ of perchloroethylene.

The jet mixer was made of PVC and was directly connected to the auxiliary tank which contained the electrolyte-absorbent solution in a close circuit with the electrolyzer and a pump. There were two kinds of jets with different throat diameter $(3.18 \mathrm{~mm}$ and 4.23 $\mathrm{mm}$ ) which directly modifies the size of the bubbles generated due to the Venturi effect, affecting to the behavior of the absorption process. The liquid flowed down the electrolytic tank over the rotameter and jet-mixer by means of a Micropump ${ }^{\circledR}$ GB $-\mathrm{P} 25$ J F5 S (flow rate $160 \mathrm{dm}^{3} \mathrm{~h}^{-1}$ ) connected to the electrochemical cell by a Tecalan ${ }^{\circledR}$ tube. The electrolytic cell was a single-compartment flow-cell DiaCell ${ }^{\circledR}$, supplied by Adamant Technologies (Switzerland). Conductive-diamond electrodes (p-Si-boron-doped diamond) were used as anode and cathode. Both electrodes were circular (100 mm diameter) with a geometric area of $78 \mathrm{~cm}^{2}$. The BDD coating have 2-3 $\mu \mathrm{m}$ of thickness, $500 \mathrm{mg} \mathrm{dm}^{-3}$ of boron concentration, and a relation $\mathrm{sp}^{3} / \mathrm{sp}^{2}>150$. The inter-electrode gap was $1 \mathrm{~mm}$. The BDD electrodes were subjected to cleaning procedure during $10 \mathrm{~min}$ in a $1.0 \mathrm{~mol} \mathrm{dm}^{-3} \mathrm{Na}_{2} \mathrm{SO}_{4}$ solution at $\mathrm{pH} 2$ (kept with some drops of sulfuric acid) at $15 \mathrm{~mA}$ $\mathrm{cm}^{-2}$ prior to electrolysis assays. All the processes were conducted at $20{ }^{\circ} \mathrm{C}$ and atmospheric pressure conditions.

To determine the viability of the absorption technology using a jet-absorber, and to clarify the behavior of PCE during this process, different preliminary non-electrolytic tests were carried out, changing the absorbent used to collect the PCE volatilized from the waste contained in the LWD tank. It is important to take in mind that one of the objectives aimed 
in this work was to simulate, in realistic conditions, the treatment of PCE released by volatilization from liquid polluted wastes, because this is one of the most common scenarios found in real applications [37-39].

2.3. Analysis procedures. Liquid and gas samples were taken from the sampling ports placed in both tanks, as it is shown in Fig. 1. Liquid samples were directly transferred to an adequate vial to measure the parameters and for gaseous sample a volume of $5 \mathrm{~cm}^{3}$ was dissolved into $10 \mathrm{~cm}^{3}$ of Milli-Q water using a glass vials with cap and PTFE Septa to guarantee that no losses of gas occur during the gas bubbling. Then, a vortex stirrer was used for $3 \mathrm{~min}$ and, finally, the samples were filtered with $0.22 \mu \mathrm{m}$ nylon filters and transferred to appropriate vials for each analysis. To determine perchloroethylene and reaction products concentrations in both gas and liquid phases, a liquid-liquid (L-L) extraction was employed before the analytical characterization. Samples of $1.0 \mathrm{~cm}^{3}$ were taken using a syringe / gas-tight (Hamilton, Switzerland), following extraction with 3.0 $\mathrm{cm}^{3}$ of hexane using a glass vials with cap and PTFE septa. The mixture was stirred with a vortex stirrer for $3 \mathrm{~min}$ at $4000 \mathrm{rpm}$ and then it was let to set for the separation of the phases. Next, the organic phase was transferred to a GC vial. For the by-products analysis, different techniques including high performance liquid chromatography (HPLC), ionic chromatography, and total organic and inorganic carbon analysis were used.

The removal of perchloroethylene was quantified by Gas Chromatography Electron Capture Detector (GC-ECD) (Thermo Fisher Scientific) using analytical column containing a TG-5MS capillary column $(30 \mathrm{~m} \times 0.25 \mathrm{~mm})$, Ni micro-electron capture detector, a split/splitless injector and ChromCard Software. Under the conditions used, the quantification limit (LOQ) of the GC-ECD was $0.1 \mathrm{mg} \mathrm{dm}^{-3}$. The flow rate of gas He was $1.0 \mathrm{~cm}^{3} \mathrm{~min}^{-1}$. The temperature of the oven was programmed as follows: $60{ }^{\circ} \mathrm{C}$ for 
$2031 \mathrm{~min}$, followed by a ramp $10{ }^{\circ} \mathrm{C} \min ^{-1}$ up to reach $260^{\circ} \mathrm{C}$, followed by $2 \mathrm{~min}$ hold. The temperature of the injector was $260{ }^{\circ} \mathrm{C}$.

For the determination of other degradation by-products originated in the treatment, two chromatographic methods were employed. The first one it was employed to analyze carbon tetrachloride by means Jasco HPLC LC-2000 with a Photometric Diode Array (PDA) MD-2018 Detector (Jasco, Japan). The mobile phase consisted of $100 \%$ of $0.1 \%$ phosphoric acid (flow rate of $1 \mathrm{~cm}^{3} \mathrm{~min}^{-1}$ ). The detection wavelength used was $280 \mathrm{~nm}$ and the temperature of the oven was maintained at $25^{\circ} \mathrm{C}$. Volume injection was set to 20 $\mu \mathrm{L}$. Trichloroacetic acid was determined using a HPLC Agilent 1100 series (Agilent Tech. USA) with a detection wavelength of $220 \mathrm{~nm}$. The ion exchange column used was Supercogel ${ }^{\mathrm{TM}} \mathrm{H}$ Column with $30 \mathrm{~cm} \times 7.8 \mathrm{~mm}$ ID. Other operating conditions are as follows: the mobile phase, $1 \%$ phosphoric acid $\left(\mathrm{H}_{3} \mathrm{PO}_{4}\right)$; column temperature, $30{ }^{\circ} \mathrm{C}$; flow rate, $0.8 \mathrm{~cm}^{3} \mathrm{~min}^{-1}$; injection volume, $20 \mu \mathrm{L}$. Inorganic carbon concentration was monitored using a Multi N/C 3100 Analytik Jena analyzer. Measurements of $\mathrm{pH}$ were carried out with an InoLab WTW pH-meter.

\section{Results and discussion}

3.1. Absorption of gaseous PCE. Figure 2 shows the evolution of perchloroethylene in the LWD and in the AES tanks of the experimental setup. In the LWD tank, it is produced a polluted gas by volatilization of the PCE contained in the liquid waste. This stream is expected to contain water and PCE vapors and it contacts with the liquid absorbent in the jet mixer, where the PCE is expected to be transported to the absorption circuit. Thus, as expected, PCE decreases in the LWD tank (Part a) and increases in the AES tank (Part b), being absorption highly influenced by the composition of the absorbent used, showing a better performance in methanol than in aqueous medium [40, 41]. Thus, the efficiency of this process seems to be controlled by the PCE solubility in the different electrolytic 


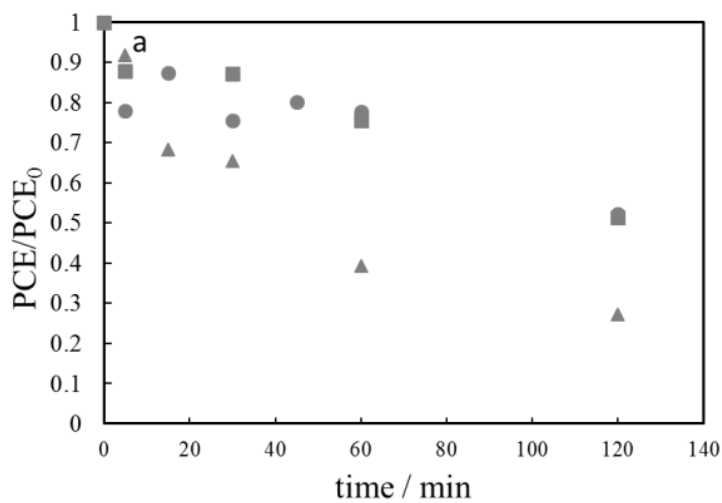
carried out[36, 37, 43].

media proposed. As previously commented, PCE has a limited solubility in water $(0.15 \mathrm{~g}$ $\left.\mathrm{dm}^{-3}\right)[42]$ and it is much more miscible in methanol, which explains the higher absorption observed in this later absorbent. By comparing the values released from the LWD tank with the accumulated in the AES tank (note that figures do not show concentrations but total amounts of PCE), it seems clear that important amounts of PCE are lost in the process in the three tests, despite of the hermeticity of the setup. They will be explained later in terms of reactivity of PCE in wet environment, which is an important point not seriously considered in previous works found in the literature, where no blank tests were

238

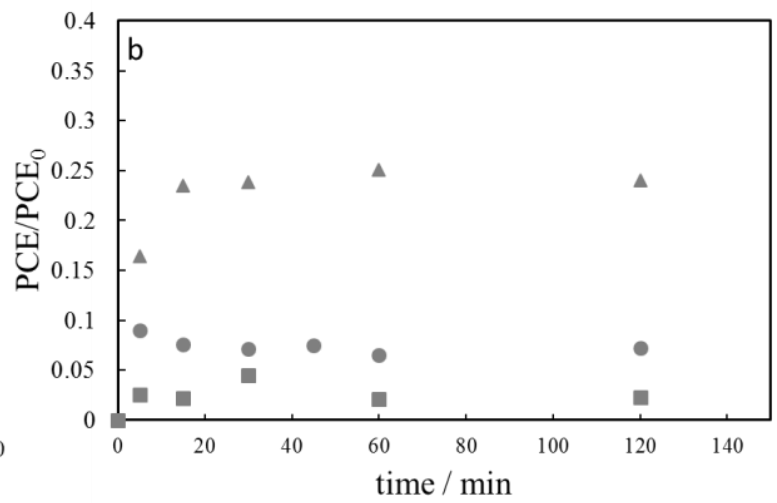

Figure 2. Evolution of the perchloroethylene with time in the LWD tank (Part a) and in the AES tank (Part b) during absorption tests carried out with different absorbents: $0.025 \mathrm{~mol} \mathrm{dm} \mathrm{Na}_{2} \mathrm{SO}_{4}$ aqueous solution; $0.025 \mathrm{~mol} \mathrm{dm}{ }^{-3} \mathrm{NaCl}$ aqueous solution; $0.025 \mathrm{~mol} \mathrm{dm}^{-3} \mathrm{NaCl}$ methanol solution.

In order to know more about the influence of the absorbent, Figure 3 shows the distribution of PCE in the liquid and gas phases in the LWD tank that contains the PCE liquid waste. Important differences are observed in the amount contained in the gas phase. The high partition coefficient in alcohol / water solutions $\left(\log K_{\mathrm{w}}=3.40\right)$ [42] may explain the lower concentration in the gas phase when the methanol is used as absorbent. In those 
conditions, absorption depletes PCE in the gas phase of the LWD tank, while the amounts of PCE in the gas phase when using aqueous absorbents are much higher. This explains the faster removal of PCE in this tank when using methanol.

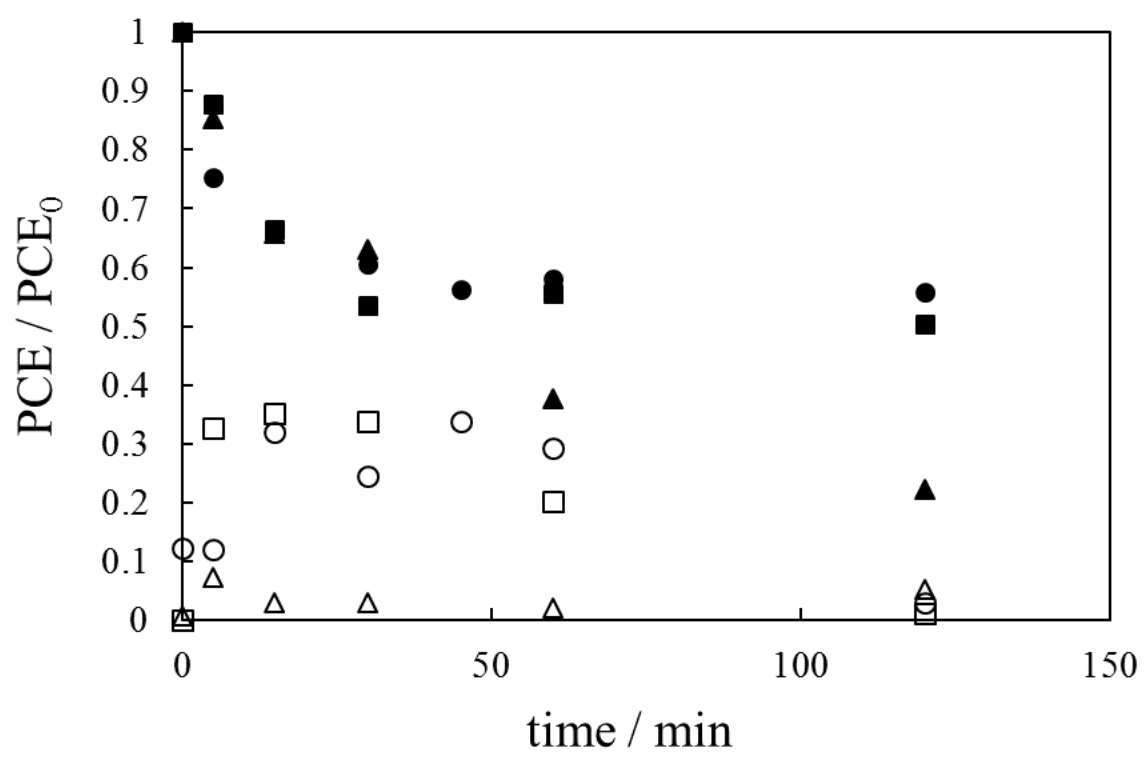

251

Figure 3. PCE contained in the liquid (full points) and gaseous (empty points) phases of the LWD tank during the absorption tests with different absorbents: $\bullet 0.025 \mathrm{~mol} \mathrm{dm}^{-3}$ $\mathrm{Na}_{2} \mathrm{SO}_{4}$ aqueous solution; $\mathbf{0} 0.025 \mathrm{~mol} \mathrm{dm}{ }^{-3} \mathrm{NaCl}$ aqueous solution $\boldsymbol{\Delta} 0.025 \mathrm{~mol} \mathrm{dm}^{-3}$ $\mathrm{NaCl}$ methanol solution.

3.2. Electro-absorption performance. To determine the changes in the absorption process performance when this technology is combined with electrolysis, several tests were carried out with the same electrolytic media tested in the absorption characterization and applying two different current densities $\left(25\right.$ and $100 \mathrm{~mA} \mathrm{~cm}^{-2}$ as a model of low and high values applied). Figure 4 shows the final percentage of PCE in the liquid and gaseous phases after the application electro-absorption technology for 120 minutes.

As it can be observed, in the AES tank, amounts of PCE are almost nil after the treatment, both in the liquid and gas phases, regardless of the current density applied and the 
absorbent-electrolyte liquid used. In comparing these results with those obtained in the single absorption process, a higher reactivity should be suggested to explain this lower amount. In fact, differences observed in the mass balance are higher than those found in the absorption process. In addition, the low concentrations of PCE in the gaseous phase of the LWD tank are not limited only to the use of methanol. Opposite, in this case they are lower than in the single absorption with the three absorbents and, in fact, values reached are very similar. This means that the electrochemically assisted reactive absorption is more efficient in depleting the PCE from the gaseous phase, because it quickly transforms the PCE absorbed into other products. Anyway, again total removal of PCE from the LWD tank is higher in the case of using methanol as compared with aqueous absorbent-electrolytes. Regarding current density applied, despite of the important differences in the values exerted, no significant differences are found in the removal of PCE. Just, it can be observed a worse performance with the use of higher current densities because it promotes competitive reactions between high amount of radicals produced [44] and the use of methanol as solvent, which can be associated to the formation of methanoate radicals in organic absorbents that are less efficient than the hydroxyl radicals produced in aqueous solutions [45, 46]. These radicals cannot be formed in pure methanol media with sodium chloride and sodium sulphate and they are known to be very important to explain the high efficiencies reached in electrolysis with diamond anodes of wastes polluted with organics [23, 47]. Anyway, in addition to the direct electrochemical processes (direct transfer of electrons on the anode surface), formation of other oxidants is obtained in aqueous and methanol absorbents[31, 46]. Thus, occurrence of peroxosulfate and hypochlorite was confirmed in sulfate and chloride medium, respectively, whose action can explain the better performance obtained in the electro-absorption process as compared to the single absorption in LWD tank. 

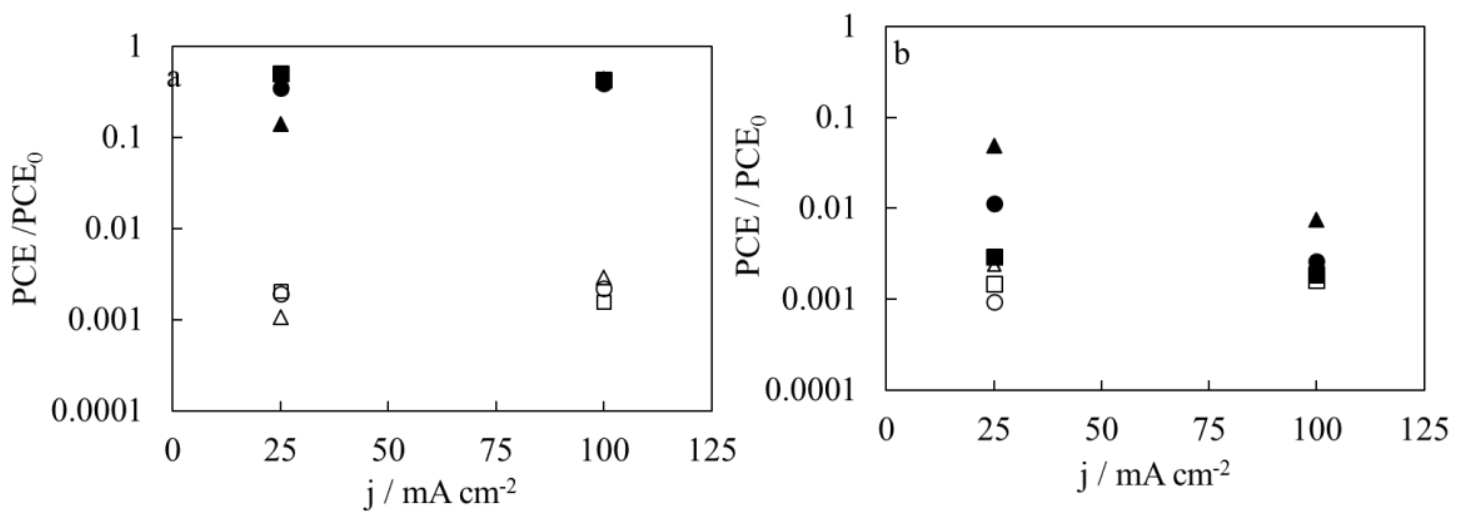

Figure 4. Influence of the current density in the distribution of perchloroethylene in the LWD tank (Part a) and in the AES tank (Part b) after 2 hours of electro-absorption treatment with different electrolytic media: $\bullet 0.025 \mathrm{~mol} \mathrm{dm}^{-3} \mathrm{Na}_{2} \mathrm{SO}_{4}$ aqueous solution; - $0.025 \mathrm{~mol} \mathrm{dm}{ }^{-3} \mathrm{NaCl}$ aqueous solution; $\boldsymbol{\Delta} 0.025 \mathrm{~mol} \mathrm{dm} \mathrm{daCl}^{-3} \mathrm{NaC}$-methanol solution. Liquid phase (full points); gaseous phase (empty points).

Hence, in connecting the absorption unit to the electrochemical cell, important differences have been observed in the distribution of PCE, indicating an important role of the electrochemically assisted reactive absorption processes that are promoted.

3.3. Influence of the bubble size produced by the jet absorber. The throat of the jet absorber is expected to have an important influence on the bubble size and, hence, on the efficiency of the absorption and electro-absorption processes. In this work, two jet absorbers have been used, one with a throat diameter of $4.23 \mathrm{~mm}$ (used in the previous sections and named in this work as coarse-bubble jet absorber or CB-JA) and other with a lower throat diameter of $3.18 \mathrm{~mm}$ (named in this work as fine-bubble jet absorber or FB-JA). For both jet absorbers, bubbles were characterized with a high-resolution camera and images were taken in the nearest point of bubble generation. To do this, an area of 4 $\times 4 \mathrm{~cm}^{2}$ was selected in a glass tank to determine the number and size of bubbles produced using Motic Images Plus 3.0 software [48]. The characterization of promoted bubbles 
307 shows differences in the diameter and number of the bubbles generated with a jet 308 absorber, as it can be seen in Figure 5. These differences may have a direct impact on the 309 effective surface area of the bubbles and, hence, they could influence on the transfer of 310 gaseous PCE into the electrolytic solution and, also, on the later distribution of PCE in 311 the liquid and gas phases. The use of the fine bubble jet-absorber increases around 31 312 times the number of bubbles generated and reduces the mean size and the variability.

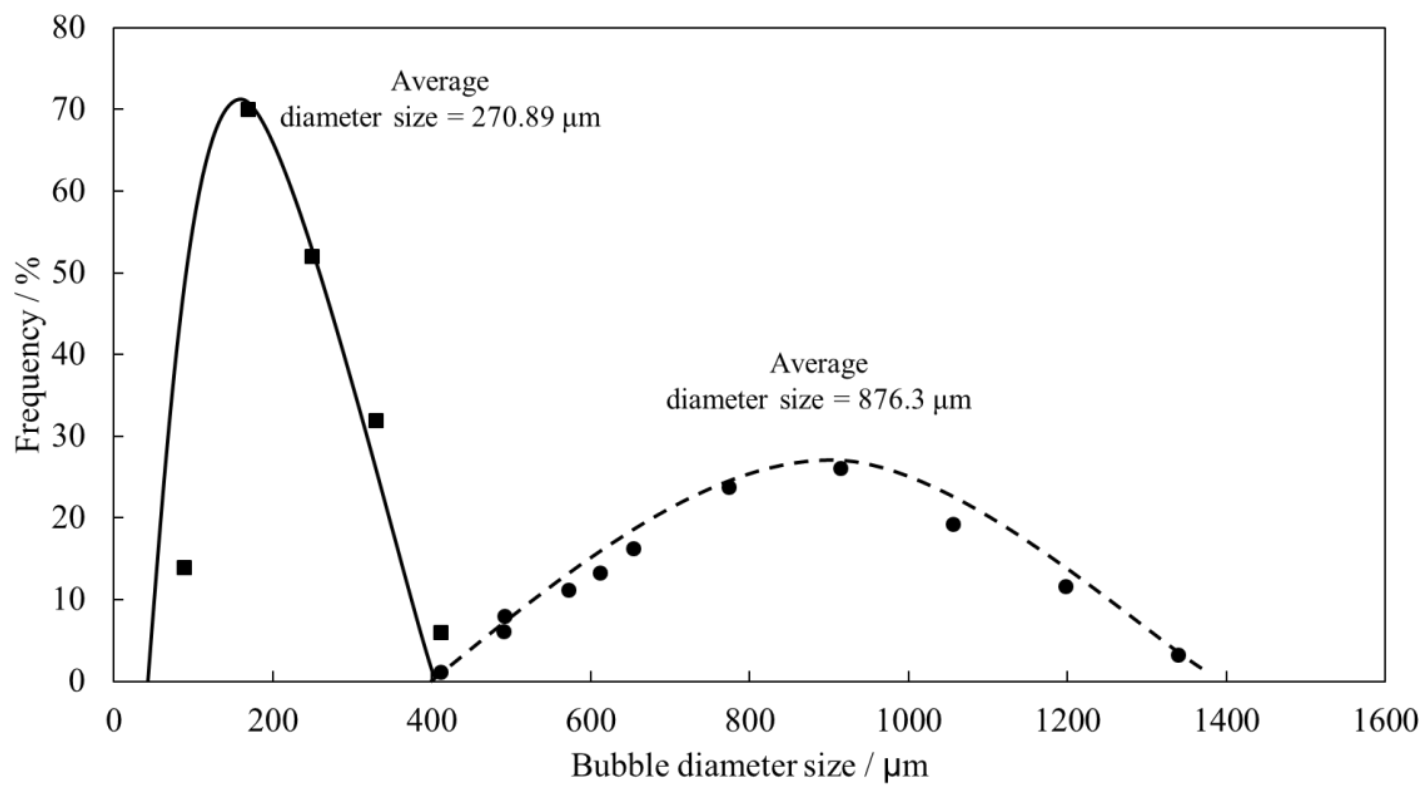

314 Figure 5. Bubble size distribution obtained with the coarse-bubble jet absorber (with a wide throat of $4.23 \mathrm{~mm})(\bullet)$, and the fine bubble jet absorber (with a tight throat of 3.18 $\mathrm{mm})(\boldsymbol{\square})$. Absorber-electrolyte: aqueous solution containing $0.025 \mathrm{~mol} \mathrm{dm}{ }^{-3}$ of $\mathrm{Na}_{2} \mathrm{SO}_{4}$

317 Once characterized the size of bubbles formed, to confirm the influence of the size and number of bubbles generated in the absorption and electro-absorption of PCE, it was proposed the evaluation of these two technologies using these two types of jet-absorbers. Figure 6 shows the total removal of PCE in the LWD and the AES tanks. 

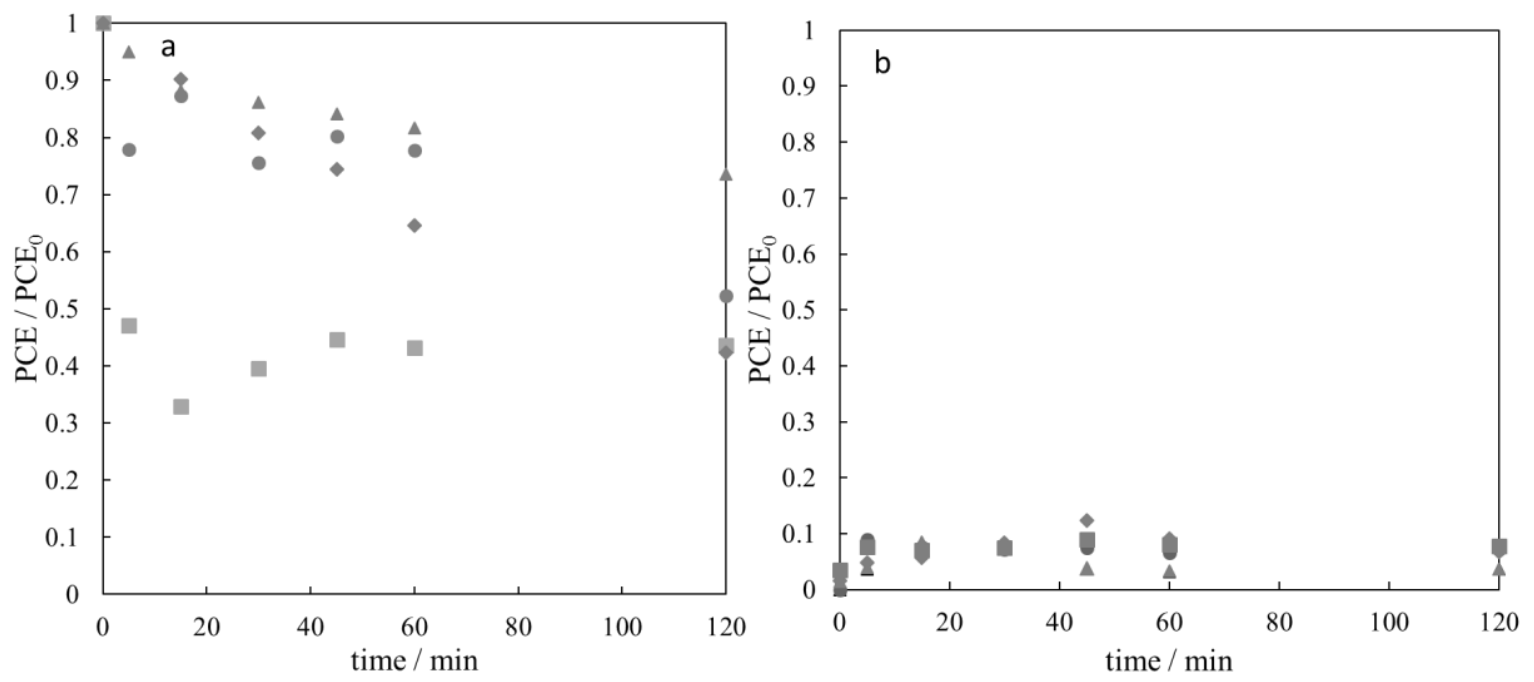

Figure 6. Changes in the amount of perchloroethylene in the LWD (Part a) and AES (part with CB-JA ( $\square$ ) and FB-JA ( $\bullet$ ). Absorber-electrolyte: aqueous solution containing 0.025 mol dm ${ }^{-3}$ of $\mathrm{Na}_{2} \mathrm{SO}_{4}$.

As seen, after 2 hours of treatment, when using the same jet absorber, the decrease of PCE in the LWD tank is higher in the electro-absorption as compared with the absorption processes, confirming the positive effect of the electrochemical process on the removal of PCE, described in the previous sections. On the other hand, in comparing the two jet absorbers, surprisingly, the decrease in PCE is higher when using the coarse-bubble jet absorber as compared with the fine-bubble jet absorber. In fact, the way in which it is produced the decrease in the PCE in this tank is very different: it is very abrupt at the beginning in the case of the CB-JA and then, the decrease slows down rapidly to almost stabilize. Opposite, it is progressive with the FB-JA with an almost constant rate of depletion (linear decrease). Regarding the PCE in the AES tank, similar very low values are reached in the four tests. Considering that decreases observed in the LWD tank do not match with increases in the AES tank, it is confirmed that in single absorption processes, there should occur also some sort of reactivity of the PCE. 
Figure 7 shows details of the distribution of PCE into liquid and gaseous phases in the

340

341

342

LWD tank. The most important information can be drawn from the gas phase: when using the fine-bubble jet absorbers the amount of PCE in the gas phases are very low in both processes. This confirms that, as expected, the absorption is more efficient with the higher specific surface area promoted by the FB-JA, favoring the transport of PCE and its absorption into the absorbent-electrolyte. Then, this species should be more easily degraded in the AES tank circuit.

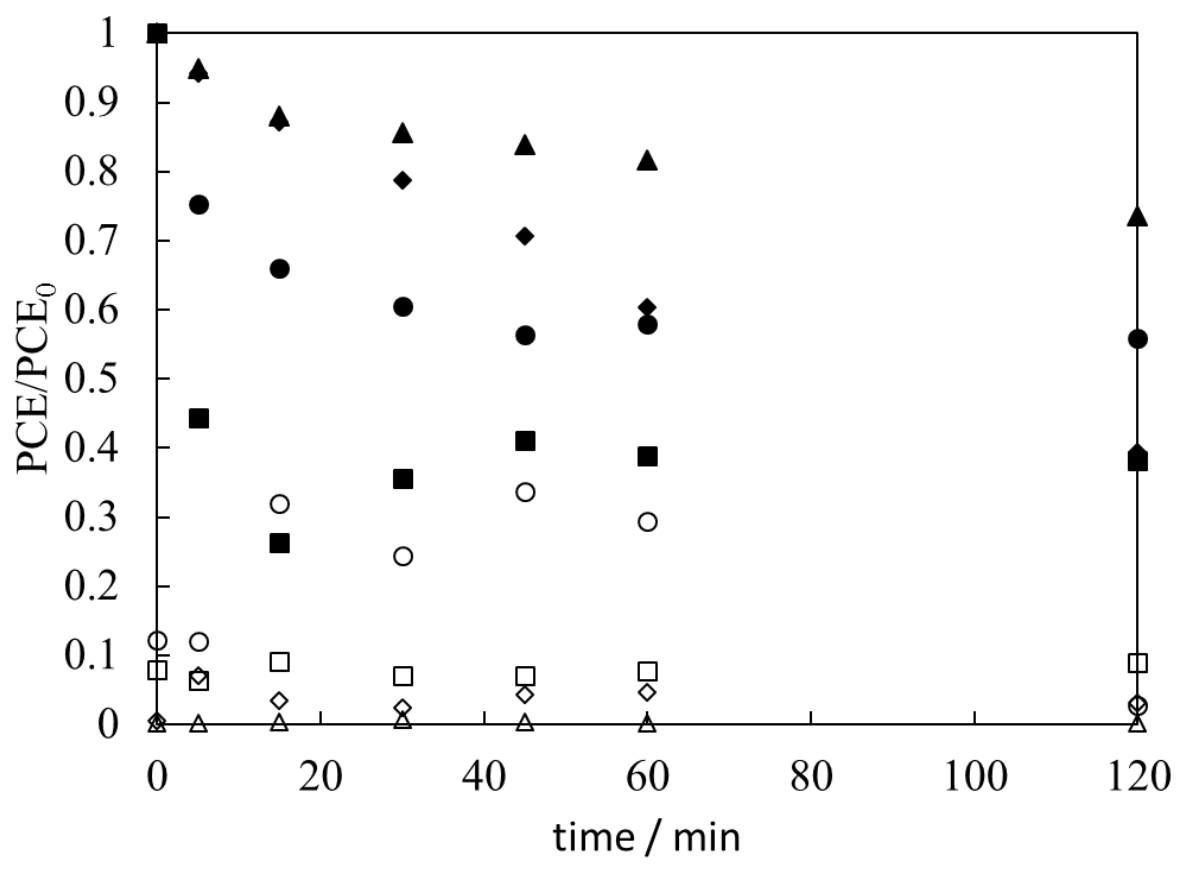

Figure 7. Distribution of perchloroethylene with the time in the LWD tank during the absorption with the coarse-bubble jet absorber $(\bullet)$ and fine-bubble jet absorber $(\boldsymbol{\Delta})$, and the electro-absorption with the coarse-bubble jet absorber (घ) and the fine-bubble jet absorber ( $\downarrow$ ). Liquid samples (full points), gaseous samples (empty points). Absorberelectrolyte: aqueous solution containing $0.025 \mathrm{~mol} \mathrm{dm}^{-3}$ of $\mathrm{Na}_{2} \mathrm{SO}_{4}$

3.4. Reactivity in absorption and electro-absorption processes. As explained in previous sections, there is no agreement between the amounts of PCE depleted in the waste LWD tank and those accumulated in the AES tank, even when no electric current 
charge is passed. Hermeticity of the system was confirmed, even at much higher pressures than those used in this work, so differences had to be attributed to reactivity. Because of that, an exhaustive characterization of intermediates using different analytical technologies, as described in the Material \& Methods Section, was carried out.

Figure 8 shows the distribution of different products detected at the end of the absorption and electro-absorption processes using the coarse and fine-bubble jet absorbers and a sodium sulfate solution as absorbent-electrolyte. As seen, main intermediates are phosgene, carbon tetrachloride and trichloroacetic acid and the differences observed in the speciation in each of the processes may indicate the promotion of different removal pathways with each technology [49-51]. In gas phase, when perchloroethylene is in contact with water vapor, this compound is known to be unstable, being transformed into phosgene. This compound mainly appeared in the set-up in which the tests with the coarse-bubble jet mixer are carried out, because the absorption in the liquid phase is not so efficient due to the higher bubble size. This lower efficiency in the absorption promotes a longer contact time of PCE with water in gas phase, in turn promoting this well-known wet decomposition pathway[37, 49]. Opposite, the transfer of PCE from the gas to the absorber-electrolyte seems to be faster with the fine-coarse jet absorber and the detection of trichloroacetic acid as the main product indicates the formation of this species by decomposition of PCE in aqueous media $[11,52]$. No phosgene is observed in this case, which is a very important information that confirms the need of long reaction times in gas phase to produce these species or, alternatively, its rapid decomposition in aqueous media. Both, the production of phosgene and trichloroacetic acid are promoted when current is applied. This indicates that electrolytic processes speed up both mechanisms, although degradation of PCE is going to occur regardless of their presence. When the absorbent does not undergo electrolysis, carbon tetrachloride seems to become the 
primary product. This compound can be formed by decomposition of phosgene and its presence is minimized when electrical current is applied, which is important considering that trichloroacetic acid is less refractory to treatments than carbon tetrachloride [53]. Carbon dioxide is only seen in the tests with the coarse-bubble jet absorber and its occurrence can be explained in terms of the well-known decomposition of phosgene into carbon tetrachloride and carbon dioxide $[39,54]$. Non-detection of carbon dioxide in the other two cases suggest a direct pathway different of that mechanism.

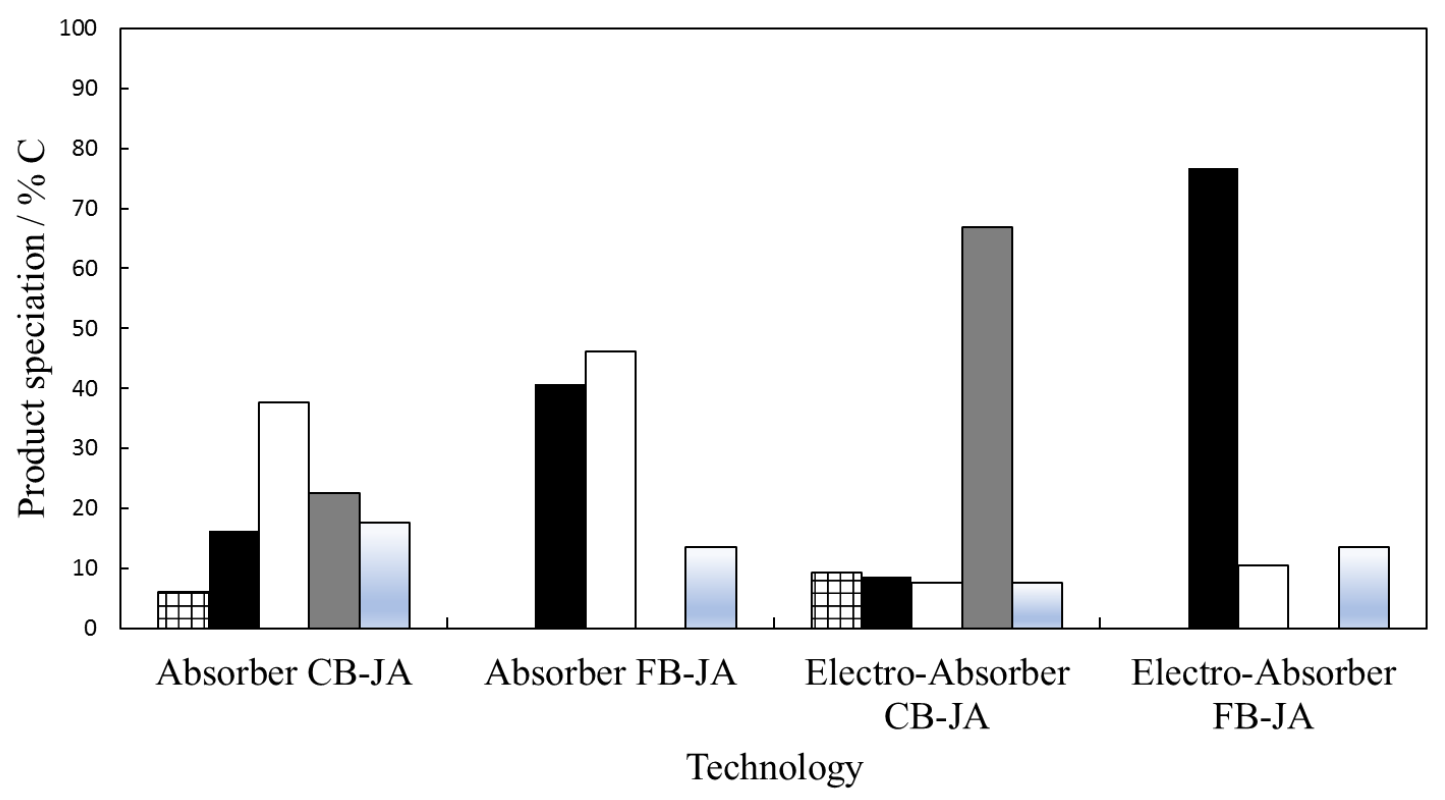

Figure 8. Products distribution obtained after a 2 hour-treatment of absorption and electro-absorption $\left(25 \mathrm{~mA} \mathrm{~cm}{ }^{-2}\right)$ with the coarse and the fine bubble jet absorbers.

Carbon tetrachloride, $\square$ trichloroacetic acid, $\square$ phosgene, $\square$ PCE, and \# carbon dioxide.

In order to determine if the absorbent-electrolyte generates differences in the removal pathways of the PCE, the evolution of main products and intermediates was also monitored in the different absorption and electro-absorption tests carried out. Figure 9 compares the products generated in the absorption and electro-absorption tests with different electrolytic media. In aqueous solutions, results at low current density indicate that phosgene is the primary product. One reason could be the nil (case of pure absorption) 
or reduced power of oxidants produced with diamond electrodes and the parasitic reactions near the electrodes of the water electrolysis that also promotes gas phase products (hydrogen or oxygen), avoiding its decomposition. Regarding to results at higher current densities, similar intermediates are obtained with sodium chloride but more quantity of carbon dioxide and trichloroacetic acid are produced, which confirms the different pathway followed in the depletion of this pollutant using electric current. In the case of sodium sulfate the phosgene is decomposed and carbon tetrachloride is formed, formation mechanism should be happening.
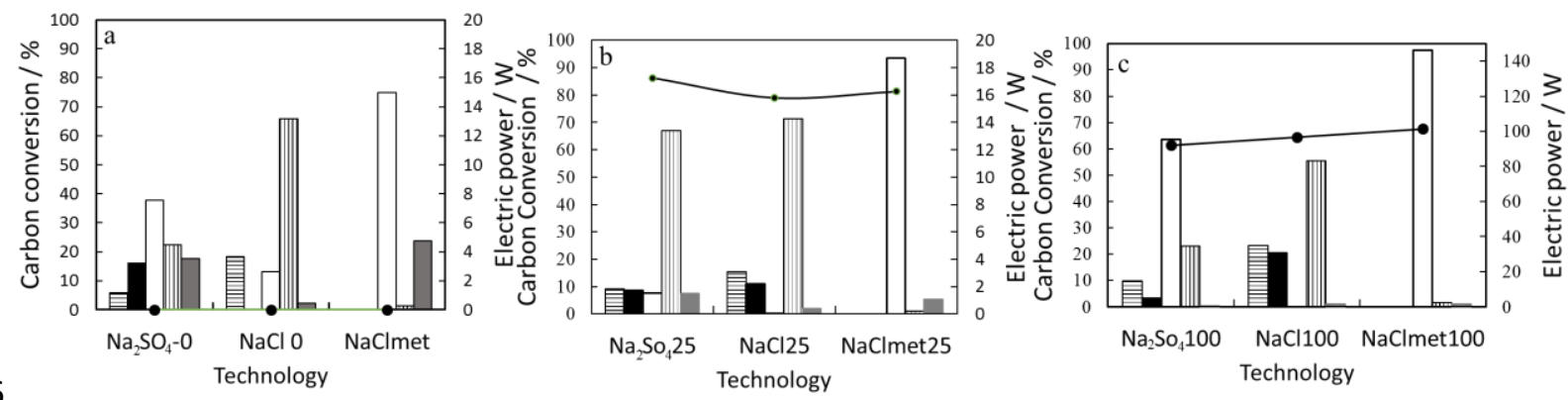

Figure 9. By-products generated and electric power consumed during absorption and electro-absorption with different electrolytic media: $\square$ carbon tetrachloride, trichloroacetic acid, $\square$ perchloroethylene, \# carbon dioxide, ${ }^{\mathbb{m}}$ m phosgene. (a) $0 \mathrm{~mA} \mathrm{~cm}^{-}$ 2 (single absorption); (b) $25 \mathrm{~mA} \mathrm{~cm}^{-2}$, (c) $100 \mathrm{~mA} \mathrm{~cm}^{-2}$.

411 The use of methanol solutions shows a diminished influence of applied the current 412 density, being carbon tetrachloride, the most important product detected at the end of the 413 process $(92-98 \%)$. In this case, it was detected an intermediate the trichloroethylene, 414 whose evolution seems to be related with the formation of carbon tetrachloride as shown in Figure 10. This supports the existence of other mechanisms for the evolution of this product different of the formation and decomposition of phosgene from PCE. 


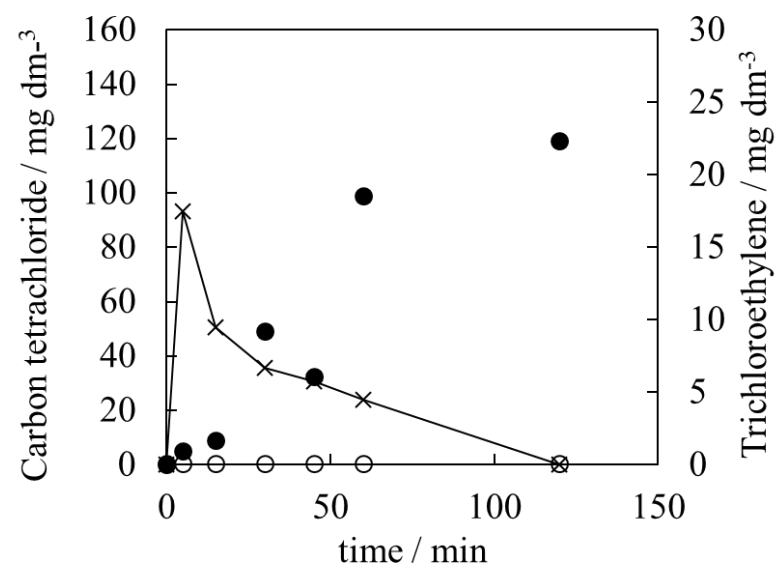

418 Figure 10. Evolution of carbon tetrachloride $(\bullet)$, trichloroacetic acid $(\diamond)$ and 419 trichloroethylene $(\times)$ during the absorption in $2.3 \mathrm{~g} \mathrm{dm}^{-3} \mathrm{NaCl} /$ methanol absorbent. Full 420 points: liquid phase; empty points: gas phase.

421 Despite jet electro-absorbers have been found to be suitable to transport PCE from a 422 polluted gas stream to a liquid absorbent-electrolyte and to modify the composition of 423 this new liquid stream, speciation results were not as expected according to the literature. 424 Perchloroethylene is not mineralized but simply transformed into other products with 425 different hazardousness, which is a serious problem that pointed out the necessity of 426 further research in this topic. This problem is not associated to the electrolysis but to the 427 wet decomposition of PCE, which activates different reactions mechanisms that occurs 428 in the liquid and the gaseous phase. Electrolysis can speed up and, to a certain extension, modify these mechanisms but further additional work has to be done. Results obtained in 430 this work pointed out that it is not only important to monitor the parent pollutant but 431 reaction intermediates and final products and initiates the path to be followed in order to 432 degrade these streams, which can be generated not only directly in industrial applications 433 but also during the treatment of liquid wastes or soils containing PCE.

\section{Conclusions}


435 From this work, the following conclusions can be drawn:

- The proposed absorption process of perchloroethylene with the jet-absorber based on Venturi effect works well and its efficiency depends on the solubility of perchloroethylene in the selected electrolytic media.

- The absorption and electro-absorption can deplete perchloroethylene but, opposite to what stated in other works, they mainly transform the perchloroethylene contained in the gaseous streams into refractory products that are sometimes more dangerous that the parent compound. Diamond electrodes, which successfully mineralize PCE in liquid wastes failed to mineralize under these conditions.

- Carbon tetrachloride and trichloroacetic acid are the main intermediates detected with absorbents consisting of sodium chloride and sodium sulfate aqueous solutions, respectively, and they represent different degradation pathways. Trichloroethylene and lower amounts of intermediates are detected in the absorption with methanol and sodium chloride.

- The size of the bubbles generated by the jet-absorber has a paramount influence on the removal pathway of perchloroethylene, pointing out the relevance of the wet degradation processes occurring in the gas phase.

- Higher current densities promote an efficient decomposition of phosgene in carbon tetrachloride in electro-absorption processes with sodium sulfate as electrolyte. Slight influence was observed with sodium chloride on aqueous and methanol solvents decreasing the phosgene and PCE compounds, respectively.

\section{Acknowledgements}


458 Financial support from the Spanish Agencia Estatal de Investigación through project 459 CTM2016-76197-R (AEI/FEDER, UE) and the Spanish Government (Grant $\mathrm{N}^{\circ}$ 460 FPU16/00067) are gratefully acknowledged. This work corresponds also to first results 461 of the Project PID2019-107271RB-I00, continuation of the CTM2016-76197-R. OGP 462 appreciates the support of the Agencia Nacional de Promoción Científica y Tecnológica 463 (ANPCyT), Consejo Nacional de Investigaciones Científicas y Técnicas (CONICET) and 464 Universidad Nacional del Litoral (UNL) of Argentina. Coordenação de Aperfeiçoamento 465 de Pessoal de nível Superior (CAPES-Brazil) through process 88881.171154/2018-01 for 466 the scholarship awarded to Fernanda L. Souza are gratefully acknowledged. 
470 [1] G.J. Nagl, Controlling H2S emissions, Chem. Eng. (London), (1997) n.p.

471 [2] A.K. Chakraborty, G. Astarita, K.B. Bischoff, $\mathrm{CO} 2$ absorption in aqueous solutions of hindered amines, Chem. Eng. Sci., 41 (1986) 997-1003.

[3] A.L. Kohl, R.B. Nielsen, Chapter 2 - Alkanolamines for Hydrogen Sulfide and Carbon Dioxide Removal, Gas Purification (Fifth Edition), (1997) 40-186.

[4] L. Chen, J. Huang, C.L. Yang, Absorption of H2S in NaOCl Caustic Aqueous Solution, Environ. Prog., 20 (2001) 175-181.

[5] P. Fang, Z. Tang, X. Chen, P. Zhong, J. Huang, Z. Tang, C. Cen, Simultaneous Removal of NOx and SO2 through a Simple Process Using a Composite Absorbent, Sustainability, 10 (2018) 4350. [6] S. Basu, Z.C. Gu, K.A. Shilinsky, Application of packed scrubbers for air emissions control in municipal wastewater treatment plants, Environ. Prog., 17 (1998) 9-18.

[7] E.J. Mrema, C. Colosio, F.M. Rubino, Pesticide Residues: Organochlorines, Encyclopedia of Food Safety, (2014) 23-30.

[8] C. Trellu, E. Mousset, Y. Pechaud, D. Huguenot, E.D. van Hullebusch, G. Esposito, M.A. Oturan, Removal of hydrophobic organic pollutants from soil washing/flushing solutions: A critical review, Journal of Hazardous Materials, 306 (2016) 149-174.

[9] O. Lugaresi, H. Encontre, C. Locatelli, A. Minguzzi, A. Vertova, S. Rondinini, C. Comninellis, Gas-phase volatile organic chloride electroreduction: A versatile experimental setup for electrolytic dechlorination and voltammetric analysis, Electrochemistry Communications, 44 (2014) 63-65.

[10] M. Keshmiri, T. Troczynski, M. Mohseni, Oxidation of gas phase trichloroethylene and toluene using composite sol-gel TiO2 photocatalytic coatings, Journal of Hazardous Materials, 128 (2006) 130-137.

[11] V. Sáez, M.D. Esclapez Vicente, Á.J. Frías-Ferrer, P. Bonete, J. González-García, Electrochemical degradation of perchloroethylene in aqueous media: An approach to different strategies, Water Research, 43 (2009) 2169-2178.

[12] C.M. Dominguez, N. Oturan, A. Romero, A. Santos, M.A. Oturan, Removal of lindane wastes by advanced electrochemical oxidation, Chemosphere, 202 (2018) 400-409.

[13] H. Monnier, L. Falk, F. Lapicque, R. Hadjoudj, C. Roizard, Intensification of G/L absorption in microstructured falling film. Application to the treatment of chlorinated VOC's - part I: Comparison between structured and microstructured packings in absorption devices, Chem. Eng. Sci., 65 (2010) 6425-6434.

[14] J.F. Pérez, J. Llanos, C. Sáez, C. López, P. Cañizares, M.A. Rodrigo, Electrochemical jet-cell for the in-situ generation of hydrogen peroxide, Electrochemistry Communications, 71 (2016) 6568.

[15] J.F. Pérez, J. Llanos, C. Sáez, C. López, P. Cañizares, M.A. Rodrigo, The pressurized jet aerator: A new aeration system for high-performance $\mathrm{H} 2 \mathrm{O} 2$ electrolyzers, Electrochemistry Communications, 89 (2018) 19-22.

[16] A. Ebadi, N.A. Khoshkholgh Sima, M. Olamaee, M. Hashemi, R. Ghorbani Nasrabadi, Effective bioremediation of a petroleum-polluted saline soil by a surfactant-producing Pseudomonas aeruginosa consortium, Journal of Advanced Research, 8 (2017) 627-633.

[17] A. Attour, M. Touati, M. Tlili, M. Ben Amor, F. Lapicque, J.P. Leclerc, Influence of operating parameters on phosphate removal from water by electrocoagulation using aluminum electrodes, Separation and Purification Technology, 123 (2014) 124-129.

[18] L.S. Pérez, O.M. Rodriguez, S. Reyna, J.L. Sánchez-Salas, J.D. Lozada, M.A. Quiroz, E.R. Bandala, Oil refinery wastewater treatment using coupled electrocoagulation and fixed film biological processes, Physics and Chemistry of the Earth, Parts A/B/C, 91 (2016) 53-60. 
[19] S. Zodi, O. Potier, F. Lapicque, J.-P. Leclerc, Treatment of the industrial wastewaters by 518 electrocoagulation: Optimization of coupled electrochemical and sedimentation processes, 519 Desalination, 261 (2010) 186-190.

520 [20] M.A. Oturan, J.-J. Aaron, Advanced Oxidation Processes in Water/Wastewater Treatment: 521 Principles and Applications. A Review, Critical Reviews in Environmental Science and 522 Technology, 44 (2014) 2577-2641.

523 [21] I. Linares-Hernández, C. Barrera-Díaz, B. Bilyeu, P. Juárez-GarcíaRojas, E. Campos-Medina, 524 A combined electrocoagulation-electrooxidation treatment for industrial wastewater, Journal of Hazardous Materials, 175 (2010) 688-694.

[22] P. Cañizares, R. Paz, C. Sáez, M.A. Rodrigo, Costs of the electrochemical oxidation of wastewaters: A comparison with ozonation and Fenton oxidation processes, Journal of Environmental Management, 90 (2009) 410-420.

[23] I. Sirés, E. Brillas, M.A. Oturan, M.A. Rodrigo, M. Panizza, Electrochemical advanced oxidation processes: today and tomorrow. A review, Environmental Science and Pollution Research, 21 (2014) 8336-8367.

[24] R.B. Moreira FC, Enric Brillas, Vítor J.P. Vilar, Electrochemical advanced oxidation processes: A review on their application to synthetic and real wastewaters, Applied Catalysis B: Environmental, 202 (2017) 217-261.

[25] O. Scialdone, S. Randazzo, A. Galia, G. Silvestri, Electrochemical oxidation of organics in water: Role of operative parameters in the absence and in the presence of $\mathrm{NaCl}$, Water Research, 43 (2009) 2260-2272.

[26] B. Marselli, J. Garcia-Gomez, P.-A. Michaud, M. Rodrigo, C. Comninellis, Electrogeneration of Hydroxyl Radicals on Boron-Doped Diamond Electrodes, Journal of The Electrochemical Society, 150 (2003) 79-83.

[27] M. Panizza, G. Cerisola, Application of diamond electrodes to electrochemical processes, Electrochim. Acta, 51 (2005) 191-199.

[28] M. Panizza, G. Cerisola, Direct And Mediated Anodic Oxidation of Organic Pollutants, Chemical Reviews, 109 (2009) 6541-6569.

[29] R. López-Vizcaíno, C. Risco, J. Isidro, S. Rodrigo, C. Saez, P. Cañizares, V. Navarro, M.A. Rodrigo, Scale-up of the electrokinetic fence technology for the removal of pesticides. Part I: Some notes about the transport of inorganic species, Chemosphere, 166 (2017) 540-548.

[30] R. López-Vizcaíno, C. Risco, J. Isidro, S. Rodrigo, C. Saez, P. Cañizares, V. Navarro, M.A. Rodrigo, Scale-up of the electrokinetic fence technology for the removal of pesticides. Part II: Does size matter for removal of herbicides?, Chemosphere, 166 (2017) 549-555.

[31] M. Muñoz-Morales, C. Sáez, P. Cañizares, M.A. Rodrigo, A new electrochemically-based process for the removal of perchloroethylene from gaseous effluents, Chemical Engineering Journal, 361 (2019) 609-614.

[32] G. Muthuraman, I.-S. Moon, A review on an electrochemically assisted-scrubbing process for environmental harmful pollutant's destruction, Journal of Industrial and Engineering Chemistry, 18 (2012) 1540-1550.

[33] B. Huang, C. Lei, C. Wei, G. Zeng, Chlorinated volatile organic compounds (Cl-VOCs) in environment - sources, potential human health impacts, and current remediation technologies, Environment International, 71 (2014) 118-138.

[34] U.S.E.P. Agency, EPA's Integrated Risk Information System, (2016).

[35] M. Bohnet, Chlorinated Hydrocarbons, Ullmann's Encyclopedia of Industrial Chemistry, (2003) 3966-4151.

[36] M.H. Kim, K.-H. Choo, Low-temperature continuous wet oxidation of trichloroethylene over CoOx/TiO2 catalysts, Catal. Commun., 8 (2007) 462-466.

[37] W. Den, V. Ravindran, M. Pirbazari, Photooxidation and biotrickling filtration for controlling industrial emissions of trichloroethylene and perchloroethylene, Chem. Eng. Sci., 61 (2006) 7909-7923. 
[38] M. Govindan, R. Adam Gopal, I.S. Moon, Efficient removal of gaseous trichloroethylene by continuous feed electro-scrubbing using a new homogeneous heterobimetallic electro-catalyst, Chemical Engineering Journal, 308 (2017) 1145-1153.

571 [39] S. Yamazaki, H. Tsukamoto, K. Araki, T. Tanimura, I. Tejedor-Tejedor, M.A. Anderson, 572 Photocatalytic degradation of gaseous tetrachloroethylene on porous TiO2 pellets, Applied 573 Catalysis B: Environmental, 33 (2001) 109-117.

574 [40] M. Muñoz-Morales, C. Sáez, P. Cañizares, M.A. Rodrigo, Improvement of electrochemical 575 oxidation efficiency through combination with adsorption processes, Journal of Environmental 576 Management, 262 (2020) 110364.

577 [41] M. MuñozMorales, C. Sáez, P. Cañizares, M.A. Rodrigo, A new strategy for the electrolytic removal of organics based on adsorption onto granular activated carbon, Electrochemistry Communications, 90 (2018) 47-50.

[42] L.M. Nijhuis N, Harrison P. ;. 9. , Tetrachloroethylene. In: WHO Guidelines for Indoor Air Quality: Selected Pollutants, World Health Organization, 9 ( 2010).

[43] J.R. González-Velasco, A. Aranzabal, R. López-Fonseca, R. Ferret, J.A. González-Marcos, Enhancement of the catalytic oxidation of hydrogen-lean chlorinated VOCs in the presence of hydrogen-supplying compounds, Applied Catalysis B: Environmental, 24 (2000) 33-43.

[44] S. Cotillas, L. Cañizares, M. Muñoz, C. Sáez, P. Cañizares, M.A. Rodrigo, Is it really important the addition of salts for the electrolysis of soil washing effluents?, Electrochim. Acta, 246 (2017) 372-379.

[45] M.J. Martín de Vidales, C. Sáez, P. Cañizares, M.A. Rodrigo, Electrolysis of progesterone with conductive-diamond electrodes, Journal of Chemical Technology \& Biotechnology, 87 (2012) 1173-1178.

[46] M. Muñoz-Morales, C. Sáez, P. Cañizares, M.A. Rodrigo, Enhanced electrolytic treatment for the removal of clopyralid and lindane, Chemosphere, 234 (2019) 132-138.

[47] C.A. Martinez-Huitle, M.A. Rodrigo, I. Sires, O. Scialdone, Single and Coupled Electrochemical Processes and Reactors for the Abatement of Organic Water Pollutants: A Critical Review, Chemical Reviews, 115 (2015) 13362-13407.

[48] C. Jiménez, B. Talavera, C. Sáez, P. Cañizares, M.A. Rodrigo, Study of the production of hydrogen bubbles at low current densities for electroflotation processes, Journal of Chemical Technology \& Biotechnology, 85 (2010) 1368-1373.

[49] S. Pitkäaho, L. Matejova, S. Ojala, J. Gaalova, R.L. Keiski, Oxidation of perchloroethyleneActivity and selectivity of Pt, Pd, Rh, and V2O5 catalysts supported on Al2O3, Al2O3-TiO2 and Al2O3-CeO2, Applied Catalysis B: Environmental, 113 (2012) 150-159.

[50] C.-c. Lee, R.-a. Doong, Enhanced dechlorination of tetrachloroethylene by polyethylene glycol-coated zerovalent silicon in the presence of nickel ions, Applied Catalysis B: Environmental, 144 (2014) 182-188.

[51] V. Sáez, I. Tudela, M.D. Esclapez, P. Bonete, O. Louisnard, J. González-García, Sonoelectrochemical degradation of perchloroethylene in water: Enhancement of the process by the absence of background electrolyte, Chemical Engineering Journal, 168 (2011) 649-655.

[52] C. Durante, B. Huang, A.A. Isse, A. Gennaro, Electrocatalytic dechlorination of volatile organic compounds at copper cathode. Part II: Polychloroethanes, Applied Catalysis B: Environmental, 126 (2012) 355-362.

[53] B.R. Helland, P.J.J. Alvarez, J.L. Schnoor, Reductive dechlorination of carbon tetrachloride with elemental iron, Journal of Hazardous Materials, 41 (1995) 205-216.

[54] R.J. Meyer, D.J. Safarik, C.T. Reeves, D.T. Allen, C.B. Mullins, Phosgene formation from adsorption of carbon tetrachloride on oxygen modified $\operatorname{Ir}(111)$, Journal of Molecular Catalysis A: Chemical, 167 (2001) 59-66. 
618 